\title{
A RELAÇÃO CIDADE-CAMPO E O CIRCUITO ESPACIAL DE PRODUÇÃO DO ALGODÃO COLORIDO ORGÂNICO.
}

\author{
Rafaela Fernandes e Silva \\ Mestre/UFPB \\ silva.rafageo@gmail.com \\ Doralice Sátyro Maia \\ Prof $^{\text {a }}$ Dra $^{\mathrm{a}} / \mathbf{U F P B}$ \\ doralicemaia@hotmail.com
}

\begin{abstract}
Resumo
O artigo tem como objetivo apresentar os resultados da análise do circuito espacial da produção do algodão colorido orgânico tendo como base a cidade de Campina Grande onde se localiza a Coopnatural. A Coopnatural é uma cooperativa que reúne desde instituições científicas e governamentais (Embrapa Algodão e Sebrae) a pequenos agricultores e costureiras envolvidos na produção do referido produto. A pesquisa deuse a partir de levantamento bibliográfico, entretanto, foram as informações e os dados obtidos na pesquisa empírica que constituem a maior contribuição aqui relatada. Foram visitados os campos de produção e os estabelecimentos responsáveis pela produção de seus derivados. A investigação ratifica que o circuito de produção do algodão colorido resulta do avanço do meio técnico-científico-informacional e que o circuito espacial produtivo do referido produto corresponde a um amplo processo, com escala internacional, mas que tem o local, mais especificamente a cidade de Campina Grande como lócus da distribuição e da gestão de todo o circuito. As transformações das relações de produção, bem como de todo o processo produtivo reforça a assertiva de qua a relação campo - cidade se transfigura, mantendo alguns resíduos de antigos processos: o trabalho informal, a exploração do trabalho agrícola e a subordinação ao mercado internacional.
\end{abstract}

Palavras chave: algodão colorido; relação cidade-campo; meio técnico-científicointernacional; Campina Grande.

\section{The relationship country-city and spatial circuit of colored organic cotton production}

\begin{abstract}
The article aims to present the results of the analysis of the spatial circuit of colored organic cotton production based on the city of Campina Grande, where it is located Coopnatural. The Coopnatural is a cooperative that brings together scientific and


governmental institutions (Embrapa Cotton and Sebrae) and seamstresses and small farmers involved in the production of product mentioned. The survey basis was a bibliographic review, however, were the information and data in empirical research that made the largest contribution reported here. We visited the fields and production facilities for the production of cotton derivatives. The research confirms that the circuit of production of colored cotton results in advance of the technical and scientificinformational circuit and that this circuit corresponds to a larger process, with an international scale, but that has the location, specifically the city Campina Grande as the "locus" of the distribution and management of the entire process. The transformation of relationships of production, as well as the entire production process itself, reinforces that the relationship country - city is transformed, holding some residue of old processes such as informal work, agricultural labor exploitation and subordination to the international

market.

Keywords: colored cotton; country-city relationships; informational-scientific-technical environment; Campina Grande

\section{Introdução}

O presente artigo traz uma análise do circuito espacial de produção do algodão colorido orgânico a partir da leitura da relação cidade-campo, desde a fase da criação de sua semente à produção e à distribuição de seus derivados, que fica a cargo da Coopnatural, cooperativa de exportação sediada na cidade de Campina Grande-PB.

$\mathrm{Na}$ atual conjuntura, de acordo com Santos (2006a, p.160), tem-se um meio que é transformado não somente por objetos artificiais, como também pela informação, estando na base da produção, utilização e funcionamento do espaço. Nesse contexto, encontra-se a ciência aplicada ao processo produtivo. A partir de então, o espaço geográfico que é produzido, tendo como suporte a ciência, a tecnologia e a informação e que segue em direção a atender os interesses dos atores hegemônicos da economia, da cultura e da política, passa por novo funcionamento, que lança um novo arranjo produtivo e também espacial.

O avanço do meio técnico-científico-informacional, levou à reestruturação produtiva os setores econômicos, entre os quais a agropecuária, implementando um novo modelo técnico, econômico e social na produção desses setores. Todos os espaços produtivos passaram a ser espaços de produção e de consumo, seja no ambiente urbano, 
seja no rural. A produção agrícola passou a receber influência das mesmas leis que regem outros aspectos da produção econômica.

Dentro desse quadro, surgiu no mercado o algodão de fibra colorida, com o intuito de atender um nascente mercado têxtil consumidor, lançado pela Embrapa Algodão, através do melhoramento convencional de espécies algodoeiras brancas e coloridas. Essa produção do algodão, agora de fibra colorida, trouxe à cidade de Campina Grande uma mudança na dinâmica socioespacial, uma vez que produziu novos espaços e novas relações de trabalho: cooperativas, ateliês de costuras, lojas especializadas, entre outros. Os atores envolvidos passaram também a compor a sociedade de forma distinta e em situações diferenciadas. São relações que se reproduziam na dinâmica da cidade.

\section{Produção do algodão colorido orgânico e o sistema de cultivo}

Ao contrário do que muitos pensam o algodão colorido não é uma criação que remeta ao século passado, a partir de processos de cruzamentos realizados pela engenharia genética. As variedades de algodão naturalmente colorido foram criadas e desenvolvidas pelas antigas sociedades indígenas e camponesas da América Central e da América do Sul, a exemplo do Peru, México e Guatemala as quais domesticaram essas fibras a partir do processo de seleção.

As comunidades utilizavam essas fibras de algodão naturalmente colorido para a fabricação de suas próprias vestimentas, do seu artesanato ou até mesmo como remédio medicinal. Ou seja, o algodão colorido, nessa época, apresentava um valor de uso, compatível com o momento em que sua utilização visava a atender as necessidades de consumo do próprio grupo.

Parafraseando Moreira (2007, p.176), a “forma societária dos homens determinava um modo de vida que pouco se distinguia das características e elementos do meio natural que o cercavam”. Este seria o primeiro período da divisão apresentada por Santos (2006a), das fases da história do meio geográfico. Para o referido autor, a história do meio geográfico divide-se em três fases: meio natural, meio técnico e meio 
técnico-científico-informacional, sendo que sua distinção se dá pelo nível de utilização e dos meios técnicos.

Para a periodização desses meios, o referido autor afirma que

Quando tudo era meio natural, o homem escolhia da natureza aquelas suas partes ou aspectos considerados fundamentais ao exercício da vida, valorizando, diferentemente, segundo os lugares e as culturas, essas condições naturais que constituíam a base material da existência do grupo. (MOREIRA, 2007, p.157)

A técnica é entendida por Santos $\left(2006^{\mathrm{a}}\right.$,) “como um meio de produção do espaço geográfico pelo qual o homem consegue modificar a natureza”. O autor afirma que a técnica é um conjunto de meios instrumentais e sociais com os quais o homem realiza sua vida, produz e, ao mesmo tempo, cria espaço. Mas a técnica deve ser entendida como a própria ação, não se tratando, apenas, de considerar as chamadas técnicas da produção, isto é, a técnica específica. Só o fenômeno técnico na sua total abrangência permite alcançar a noção de espaço geográfico. (SANTOS 2006a).

No primeiro período, as técnicas foram empregadas de modo a atender as necessidades de uma sociedade local. Assim, as técnicas utilizadas eram criadas a partir das necessidades dessa mesma sociedade. Os sistemas técnicos, nessa fase, eram formados pelo que o autor denomina de objetos culturais e objetos naturais.

Quando o espaço se tornou mecanizado, ele passou a ser formado não apenas por esses objetos, mas também pelos objetos técnicos. Eram objetos concretos, que apresentavam um "uso possível”, correspondendo ao meio ou resultado entre os requisitos de uma atividade técnica. Tinha-se, então, o "componente natural unido ao artificial” (MOREIRA, 2007, p. 177), pelo jogo da razão comercial em prol da razão da natureza. Os lugares se diferenciavam pela extensão e pela densidade da substituição dos objetos culturais e naturais por objetos técnicos.

No terceiro e último período, o meio foi transformado não somente por objetos artificiais, mas também pela informação, estando na base da produção, utilização e funcionamento do espaço: era a ciência aplicada ao processo produtivo. A partir daí, tivemos um espaço geográfico produzido com base na ciência, na tecnologia e na 
informação, que seguiu em direção a atender os interesses dos atores hegemônicos da economia, da cultura e da política. Agora,

\begin{abstract}
Rompem-se os equilíbrios preexistentes e novos equilíbrios mais fugazes se impõem: do ponto vista da quantidade e da qualidade da população e do emprego, dos capitais utilizados, das formas de organização das relações sociais etc. Conseqüência mais estritamente geográfica, diminui a arena da produção, enquanto a respectiva área se amplia. Restringe-se o espaço reservado ao processo direto da produção, enquanto se alarga o espaço das outras instâncias da produção, circulação, distribuição e consumo.
\end{abstract} (SANTOS, 2006a, p.161)

Trata-se de um novo arranjo nas diferenças que regem o funcionamento do espaço, fazendo florescer especializações produtivas, com os objetos técnicos subordinados à lógica global da produção, que faz com que o espaço funcione como uma unidade. Todos os espaços produtivos passam a ser espaços de produção e de consumo, sejam urbanos ou rurais.

Esse novo quadro de produção econômica faz com que os espaços se tornem cada vez mais interligados, conseqüência da subordinação da lógica global da produção. Nesse sentido, são redefinidas as relações cidade-campo, hoje atreladas à superposição das formas, entendida aqui não como uma anulando a outra, mas agindo em parceria.

A idéia da superação dessa relação, a partir das relações de produção, é trabalhada por Lefebvre (2001, p.75). Para o autor, “não há uma neutralização recíproca e sim um deslocamento da oposição e do conflito, atuando agora este último entre a vida urbana e a rural e não mais entre a cidade e o campo".

O autor baseia-se na hipótese da sociedade urbana. Para ele, a sociedade urbana nasce com o desenvolvimento da industrialização, tratando-se de uma sociedade virtual, inacabada, ou seja, que ainda se encontra em processo de formação. Esse processo de industrialização e a formação da sociedade urbana irão levar à expansão do tecido urbano, fazendo com que a sociedade e a vida urbana penetrem no campo. Para Lefebvre (2001),

O tecido urbano prolifera, estende-se, corrói os resíduos de vida agrária. Estas palavras, "o tecido urbano”, não designam, de maneira restrita, o domínio edificado nas cidades, mas o conjunto das 
manifestações do predomínio da cidade sobre o campo. (LEFEBVRE, 2004, p. 17)

A esse processo de ampla urbanização, que atingiu o campo e todo o espaço nacional brasileiro, dentro de uma lógica urbano-industrial integrada por condições gerais de produção equivalentes e por um consumo coletivo de base industrial, MonteMór (2007, p.98) chama de urbanização extensiva, em que o "meio urbano deixa de ser o espaço da cidade para se transformar no espaço social total”. Isso nos mostra um mundo urbano que penetra cada vez mais no campo, modificando os costumes da vida rural e dinamizando a relação entre esses dois espaços.

Essa expansão do modo de viver do urbano até os campos de produção foi decorrência, então, não apenas do avanço do meio técnico-científico-informacional que mudou toda base de relação da produção, que surgiu, como vimos anteriormente, a partir da transformação do meio por objetos artificiais, pela informação e pela entrada da ciência ao processo produtivo - mas também do avanço do tecido urbano, com a consequente ampliação da divisão técnica e social do trabalho, acabando por provocar mudanças profundas nas relações.

O avanço do meio técnico-científico-informacional levou à reestruturação produtiva dos setores econômicos, demarcada pela transição do regime de cumulação fordista para o flexível. Segundo Whitacker (2010)

O termo reestruturação vem sendo aplicado há vários anos para retratar momentos do processo de produção hegemônico [capitalismo], em seu sentido mais amplo, que congrega tanto a produção em si, quanto o consumo e a reprodução, que sejam marcados por rupturas, por mudanças profundas e pela constituição de paradigmas postos à análise científica. [...] Trata-se de processos que identificamos com a tensa e complexa coexistência do sistema fordista de produção com o regime de acumulação flexível. (WHITACKER, 2010)

A reorganização do regime de acumulação, ou seja, a reestruturação econômica acompanhada da reestruturação produtiva, acarretou a reestruturação da agropecuária, implementando um novo modelo técnico, econômico e social na produção desses setores. Com o modo flexível de acumulação e produção houve uma intensificação de produtos ofertados pelas indústrias, diversificando as oportunidades de consumo. 
Desse modo, surgiu a possibilidade da formação de setores têxteis e confecções que atendam as necessidades de roupas dos mais diversos e diferentes nichos de mercado (FARIAS, 2010).

No nosso entendimento, esse conjunto de eventos que marca a passagem do fordismo/keynesianismo para a acumulação flexível/neoliberalismo é cheio de possibilidades para a transformação do algodão colorido e de seus manufaturados em mercadorias com valores de troca [...] (FARIAS, 2010, p. 110)

Nesse contexto, de reestruturação produtiva, em especial da agropecuária, surgiu o que se denomina hoje de agricultura científica, que oferece novas possibilidades para a acumulação ampliada do capital, guiada pela economia de mercado, em função das demandas urbanas e industriais.

Como afirma Santos (2006b),

Os últimos séculos marcam, para a atividade agrícola, com a humanização e a mecanização do espaço geográfico, uma considerável mudança de qualidade, chegando-se recentemente, à constituição de um meio geográfico a que podemos chamar de meio técnico-científico-informacional, característico não apenas da vida urbana, mas também do mundo rural, tanto nos países avançados como nas regiões mais desenvolvidas dos países pobres. É desse modo que se instala uma agricultura propriamente científica, responsável por mudanças profundas quanto à produção agrícola e quanto à vida de relações. (SANTOS, 2006a, p. 88)

Sabe-se que as novas dinâmicas dos espaços agrícolas ocorreram a partir de uma flexibilização do trabalho no campo, que atingiu tanto a base técnica quanto a econômica e social do referido setor, acelerando, dessa forma, um processo de reorganização e adquirindo capacidade de propagação dos capitais industriais e financeiros. Isso porque o campo apareceu como suscetível à introdução do capital tecnológico, já que em seu espaço não estava contida uma grande quantidade de rugosidades, o que facilitou a instalação de fixos em seu espaço e uma propagação do meio técnico-científico-informacional (SANTOS, 2006b, p. 46). O campo despontou na fase atual da globalização da economia como nova possibilidade para a acumulação ampliada do capital. Ocorreu, assim, uma significativa mudança quanto à produção 
agrícola, que passou a ter uma referência planetária, recebendo influência das mesmas leis que regem os outros aspectos da produção econômica (SANTOS, 2006b).

Cada vez mais integrada ao circuito da economia urbana, a agricultura científica impôs novas relações entre a cidade e o campo. A produção agrícola passou a atender uma demanda de mercado consumidor industrial. O campo, nesse momento, absorveu grande número de máquinas, insumos químicos e biotecnológicos, fornecidos pela atividade industrial. Dessa maneira, alterou-se a relação cidade-campo, desencadeada pelas necessidades do consumo produtivo agrícola que, com esse quadro, tem crescido mais rapidamente do que o consumo consumptivo. De acordo com Elias (2003),

[...] uma das principais orientações da pesquisa tecnológica na agricultura teve como intuito a produção de insumos artificiais, fabricados em escala industrial, capazes de substituir parte dos insumos naturais e, assim, ter maior controle sobre o ciclo biológico das plantas e dos animais, deixando-o um pouco menos vulnerável e, em conseqüência, capaz de responder mais positivamente às novas formas de produção, distribuição e consumo (ELIAS, 2003, p. 61).

Essa modernização, portanto, significou uma transformação da base técnica de produção, fazendo a agricultura depender cada vez mais de compras industriais e de serviços técnicos e financeiros para a produção de suas mercadorias, tornando-se um mercado de meios de produção industriais.

Diminuiu-se a dependência do setor agrícola em relação aos fatores naturais, possibilitando ainda mais a entrada deste ramo no mercado global. Por sua vez, essa inserção, cada vez mais forte, ligada à expansão do capitalismo no campo, introduziu atividades industriais direcionadas ao desenvolvimento da agropecuária, as agroindústrias.

A indústria e a vida urbana tornaram-se o novo centro da economia, impondo suas demandas ao setor agrícola. A organização de atividades agrícolas integradas às indústrias fez surgir os complexos agroindustriais (CAIs), que, no dizer de Elias (2003),

seriam compostos pelos diversos setores industriais que se desenvolvem atrelados à agricultura moderna, tanto os que produzem insumos e bens de capital para a mudança de sua base técnica (fertilizantes, adubos, tratores, sementes, etc.), quanto o de processadores dos produtos agropecuários. (ELIAS, 2003, p. 170) 
Dando seqüência à análise, a partir das palavras de Marafon (2009), a formação desses complexos agroindustriais transformou a produção agrícola em agronegócio, tendo sido incorporado ao processo produtivo tratores, colheitadeiras, produtos químicos e sementes selecionadas. Dessa maneira, a produção agrícola passou a atender uma demanda de caráter urbano-industrial.

Apesar da inclusão da cientificidade e da tecnologia na agricultura ter acarretado grandes mudanças no espaço rural brasileiro, desde profundas alterações na divisão do trabalho, na produção e no consumo, ela não trouxe uma mudança homogênea, pois se inseriu de forma desigual no território do Brasil. Por conta disso, podemos falar em modernização da agricultura no território brasileiro, somente para alguns setores como o da produção da soja, da laranja, da cana, entre outros produtos, não correspondendo pois, a toda a produção agropecuária brasileira.

Graziano da Silva (1996, p. 9), ao estudar a transição do complexo rural brasileiro aos complexos agroindustriais (CAIs), mostra que, no Brasil, a modernização agrícola deu-se de forma diferenciada. Em lugares que dispunham de excedente, de base capitalista mais avançada, onde se destacou o surto da industrialização brasileira, essa modernização sobreveio de forma mais intensa, como aponta:

A divisão regional do trabalho, que se estabelece a partir do momento em que São Paulo se consolida como núcleo dinâmico do processo de industrialização, implica a definição de uma "periferia" que se explica basicamente em função de seu "atraso histórico" em relação ao pólo dinâmico, até que se altere o padrão da acumulação (GRAZIANO DA SILA, 1996, p. 9)

E segue:

[...] dada a desigualdade na origem (pelo maior avanço do complexo cafeeiro paulista), as regiões periféricas - basicamente Norte e Nordeste, Minas Gerais e parte do Centro-oeste, não conseguem atingir o grau de modernização da agricultura paulista ou sulina. Apesar do ritmo acelerado de incorporação do progresso técnico, tais regiões não elevam proporcionalmente os níveis de produtividade, alargando as disparidades regionais. (GRAZIANO DA SILA, 1996, p.10) 
Apesar do histórico da desigualdade regional, graças ao avanço do meio técnicocientifico-informacional, todas as regiões passaram a se integrar no que diz respeito à produção, como esclarece Elias (2003):

o desenvolvimento de novas tecnologias e a expansão do meio técnico-cientifico-informacional possibilitaram a dispersão espacial da produção, redefinindo os padrões locacionais das indústrias, que passaram também a ocupar a periferia do território nos países subdesenvolvidos (ELIAS, 2003, p.114).

O avanço desse meio levou à reestruturação produtiva vários setores da economia, chegando à reestruturação da agropecuária. Isto é, as relações que se estabelecem no setor agropecuário bem como os fixos instalados no setor foram reestruturados com a introdução da ciência, da tecnologia e da informação.

Retomando Elias (2003), os vultosos investimentos públicos e privados, para o financiamento da modernização agrícola, foram determinantes para esse processo de inovações vindas de fora da região e mesmo do país.

Um dos órgãos estatais criados para financiar pesquisas direcionadas ao desenvolvimento da atividade agrícola foi o Centro Nacional de Pesquisa do Algodão, inserido na Embrapa Algodão, que tem como finalidades: gerar e transferir tecnologias de baixo impacto ambiental; desenvolver cultivares de algodão resistentes a doenças e adaptadas às condições do cerrado brasileiro; desenvolver cultivares de algodão adaptadas ao cultivo na região semiárida; desenvolver cultivares de amendoim, gergelim e mamona adaptadas ao cultivo do Nordeste; fortalecer a agricultura familiar e o agronegócio; descobrir novas aplicações para produtos estudados e integrar a agricultura à indústria e ao consumidor.

Essa reestruturação alcançou o cultivo do algodão. No Centro-Sul do país encontram-se os maiores produtores de algodão, com cultura altamente tecnificada. A difusão, então, do conjunto de inovações da atividade agropecuária alcançou por completo a cultura do algodão no Centro-Sul do país, quando, na década de 1990, a Embrapa Algodão passou a promover pesquisas objetivando o desenvolvimento de 
cultivares de algodão adaptáveis às condições do cerrado brasileiro. Em outras palavras, foram adotadas medidas como de correção do solo, grande emprego de máquinas, utilização de insumos químicos, aumentando a dependência do cultivo do algodão ao processo científico e técnico de base industrial.

O algodão plantado no Mato Grosso teve destaque a partir de 1995, após a denominada "crise do Bicudo"2 ter-se alastrado na plantação de algodão em todo o Brasil, principalmente na região Nordeste. Souza (2009), ao estudar a produção do algodão no Mato Grosso, destaca:

O novo perfil da cultura é caracterizado pelas grandes plantações, com áreas que se estendem de 100 a 3000 mil hectares, alta mecanização, com adubação pesada, uso de herbicidas, fungicidas, inseticidas e reguladores de crescimento e descaroçamento feito na própria propriedade, permitindo ao produtor a venda direta às indústrias têxteis. (SOUZA, 2009, p. 18)

Com a alta inserção da tecnologia na plantação, o cultivo passou da pequena para a grande propriedade, O referido autor aponta para as redes técnico-produtivas do algodão no Mato Grosso, afirmando que são reflexos da transformação por que passo a agricultura brasileira:

Todo esse conjunto de transformações acontecidas na agricultura brasileira com destaque para a cotonicultura de Mato Grosso, foram às responsáveis pelas recentes mudanças ocorridas no mercado nacional de algodão seus impactos se mostram na dificuldade de pequenos investimentos e pequenos produtores de se adequarem a este tipo de produção o território se articula em rede a novos circuitos espaciais de produção exigindo novos círculos de cooperação, novas redes se formam, o trabalhador utilizado para a lavoura deve ser especializado e qualificado no uso de maquinário de adubação e colheita, numa nova divisão territorial do trabalho as etapas de beneficiamento das plumas e descaroçamento feito nas próprias fazendas. (SOUZA, 2009, p.19)

Entretanto, de maneira tímida, se comparada às agroindústrias brasileiras, essa modernização alcançou os espaços produtivos do algodão colorido, cujo cultivo da fibra não se dá em grande escala, pois está direcionado a um mercado consumidor restrito, pois é realizado em pequenas propriedades, fortalecendo o regime familiar. 
Atualmente a Embrapa Algodão, criada em 1975, localizada na cidade de Campina Grande-PB, vem desenvolvendo pesquisas relacionadas a melhoria da fibra do algodão colorido. Na empresa funciona o Centro Nacional de Pesquisa do Algodão ${ }^{3}$ (CNPA) que, nos dias atuais, está direcionado, além dos cultivos de algodão e sistemas de produção, ao desenvolvimento de pesquisas nas áreas de controle biológico, biotecnologia, mecanização agrícola e qualidade de fibras e fios de algodão.

Não só a ciência, mas também a tecnologia e a informação, estão contidas na criação dessa semente, que faz com que o algodão já nasça colorido, a partir de pesquisas e experimentos. Tais pesquisas são desenvolvidas por engenheiros agrônomos que trabalham com o Melhoramento Convencional, ou seja, o cruzamento entre o próprio algodão, o branco, que possui uma fibra mais resistente, com o outro que apresenta alguma coloração, mas tem a fibra fraca. Essas fibras com coloração, utilizadas para o processo de melhoramento, são fibras nativas, não só do Brasil como de outros países e já apresentam uma coloração marrom ou esverdeada, sendo, porém curtas, o que dificulta o processo de fiação ${ }^{4}$.

Esse processo de melhoramento da fibra do algodão dura entre sete a nove anos, sendo realizado com várias cores concomitantemente. A primeira coloração resultante foi lançada em 2000, a BRS 200 marrom, a partir do cruzamento natural entre o algodão mustellinum nativo do Nordeste, que produz pluma marrom, com o algodão mocó, de fibra branca, mais resistente, originário do Caribe, mas também anteriormente produzido no Nordeste brasileiro. Em 2002 foi lançada a BRS verde, oriunda do cruzamento entre CNPA 7H, herbácea de fibra branca, e a Arkansas Green. Posteriormente, em 2005, a Embrapa criou a BRS safira, de coloração vermelha e a BRS rubi. A última, lançada em 2010, foi a topázio. Todas com fibras de alta resistência podem servir às indústrias modernas. Em muitos casos, sua produção é livre de fertilizantes, pesticidas e herbicidas químicos, o que eleva o preço do produto.

Após a criação das sementes, a Embrapa Algodão, vende-as a cooperativas que as distribuem aos agricultores, localizadas em sua maioria na cidade de Campina Grande - PB.

O cultivo do algodão orgânico realiza-se dentro de um sistema que fomenta a atividade biológica, estimula a sustentabilidade e exige um manejo diferente do sistema Geo UERJ - Ano 13, no. 22, v. 1, $1^{\circ}$ semestre de 2011 - ISSN 1981-9021 http://www.e-publicacoes.uerj.br/index.php/geouerj 
de produção convencional (SOUZA, 2000). E, para ser considerado como orgânico, toda a cadeia produtiva passa por uma inspeção e certificação. A autora afirma ainda que a iniciativa de produzir tecido orgânico e colorido no Brasil foi de uma empresa de tecidos artesanais de São Paulo que já trabalhava com algodão orgânico.

Toda a cadeia produtiva do algodão colorido orgânico aqui analisada é inspecionada pelo IBD (Instituto Biodinâmico de Desenvolvimento Rural), que garante o selo de orgânico a toda a produção da cooperativa. A inspeção ocorre desde a produção do algodão até o processo da transformação da matéria-prima nas respectivas mercadorias.

Junto às pesquisas da Embrapa Algodão estão presentes técnicas para essa produção orgânica, que são levadas ao agricultor para o desenvolvimento da sua produção. Os experimentos dão-se justamente com base na troca de conhecimentos e da vivência do campo com a tecnologia da empresa.

Entre as técnicas levadas ao agricultor, observadas em trabalho de campo, destacam-se as diferentes maneiras de combate às pragas, realizadas através de rotação de culturas. Os agricultores adotam o consórcio do algodão com outras plantas, como, por exemplo, o cultivo do coentro cuja folha atrai a joaninha que come uma das plantas invasoras do cultivo do algodão: o pulgão.

Outro beneficiamento dos consórcios de cultivo é o melhoramento no crescimento do algodão. Junto ao coentro, utilizam-se a batata doce, o feijão, o gergelim, o amendoim, a mandioca, entre outros que, além de favorecer o crescimento do algodão, contribuem para a obtenção de uma renda ou mesmo para a subsistência. Figura 1.

Figura 1 


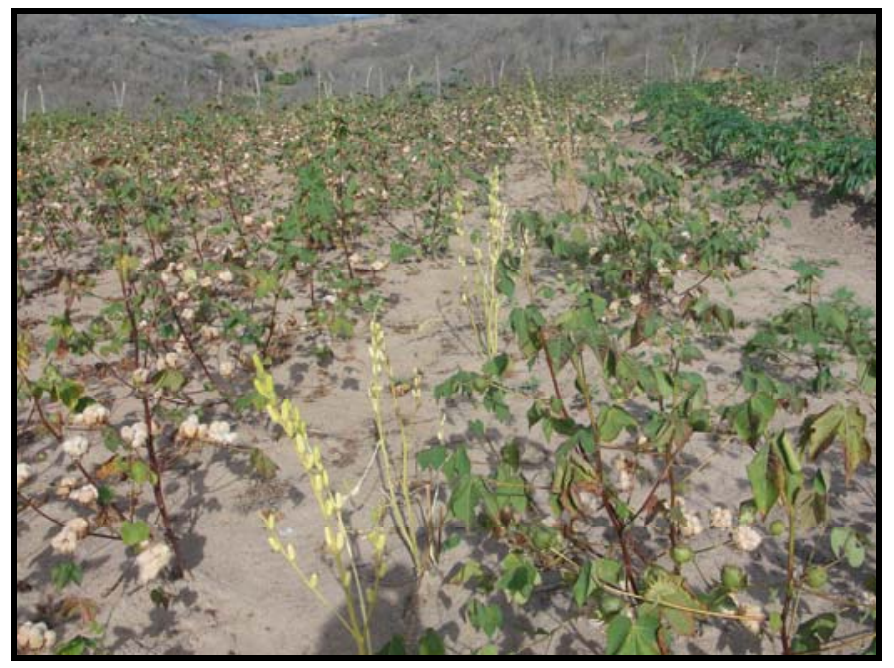

Foto: Plantação algodão colorido orgânico, variação topázio em consórcio com gergelim e mandioca. Fonte: Trabalho de campo, 2010. Foto: Rafaela Silva.

Em trabalho de campo, na comunidade Poço do Gado, localizada no município de Arara ${ }^{5}$, interior da Paraíba, um agricultor relatou que já utilizava o consórcio com o feijão, mas de uma maneira diferente. Quando o feijão já estava amadurecendo, plantava o algodão. Hoje, o consórcio é realizado concomitantemente e não apenas com o feijão, mas também com outros produtos como o milho. Essa alteração foi necessária, porque, como o feijão absorve muita água, esse consórcio acaba não sendo tão eficiente como outros, a exemplo do gergelim.

Na comunidade Poço do Gado o sistema de cultivo é o sistema de sequeiro, isto é, depende dos dias chuvosos para irrigar a plantação. Tanto o processo de semeadura como o da colheita são realizados a mão ${ }^{6}$. A comunidade começou a plantar o algodão colorido em 2009 e a Embrapa forneceu $7 \mathrm{~kg}$ de semente para cada produtor, servindo de experimento para o cultivo da nova variedade, o algodão colorido de fibra topázio.

Podemos perceber que a Embrapa Algodão utiliza-se de experimentos tanto para o combate a pragas como para a diversidade na forma de cultivo. Alguns dos produtos cultivados (gergelim, amendoim, trigo) no consórcio com o algodão são derivados de suas pesquisas, sendo as sementes cedidas ao agricultor.

A fase de beneficiamento/descaroçamento é um processo bastante delicado. Após a retirada da pluma, o caroço retorna para a área de cultivo, e ocorre em descaroçadeiras instaladas nas comunidades plantadoras do algodão. 
O mapa 1 mostra os municípios, localizados no estado da Paraíba, onde se dá a plantação do algodão orgânico de fibra colorida e os campos de cultivo onde foi realizada a pesquisa.

Mapa 1 


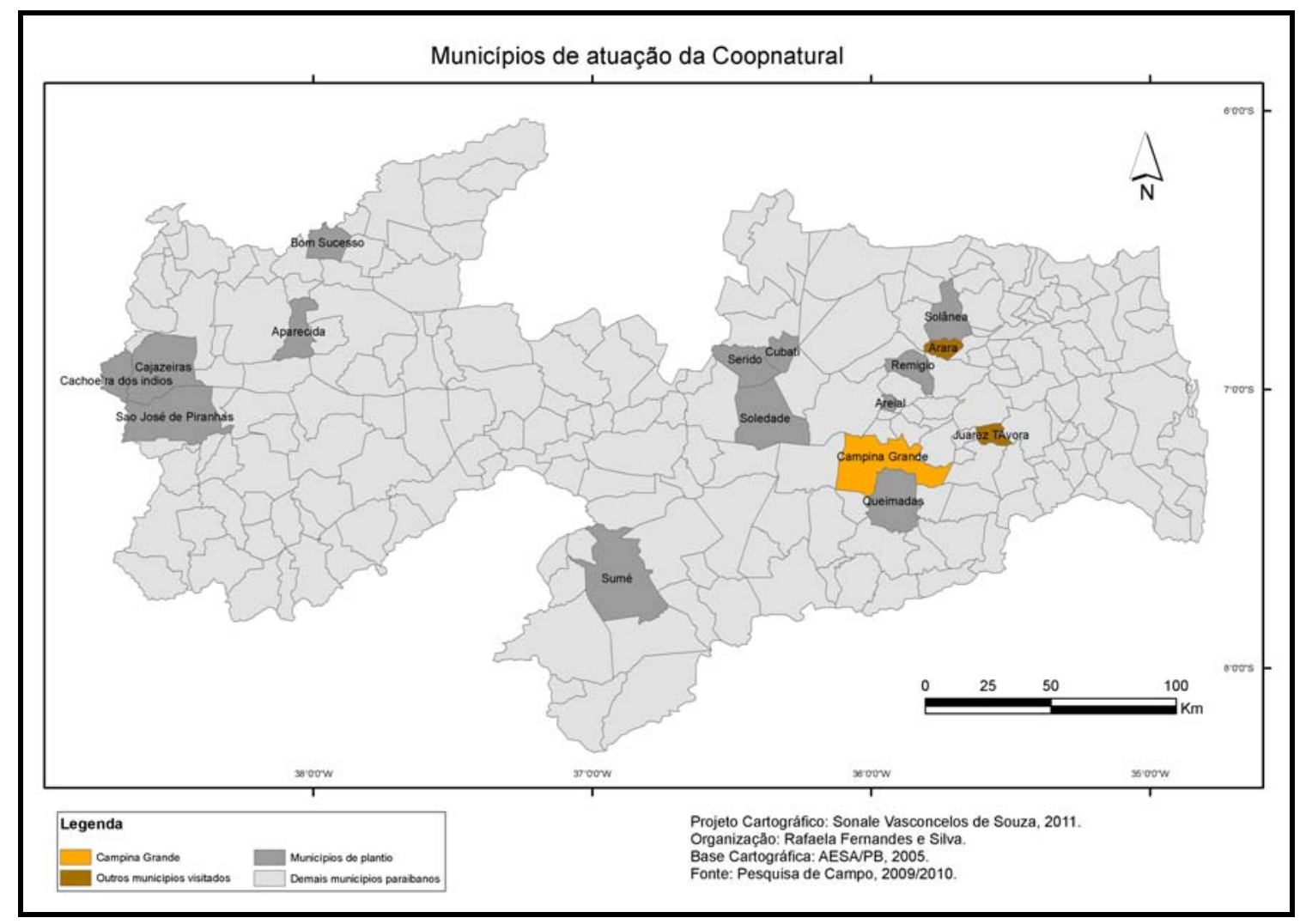

A partir do mapa 1, podemos observar a distribuição do plantio do algodão colorido no território paraibano, sob a gestão da Coopnatural, sediada em Campina Grande, onde os produtos são distribuídos para serem comercializados. Os plantios estão divididos em 15 municípios, dos quais 2 foram visitados.

No município de Remígio o cultivo funciona dentro de uma área de assentamento: Queimadas. Este foi o pioneiro na relação da cooperativa e assentamento, destacando-se pelo cultivo da fibra BRS verde.

Já o assentamento Margarida Maria Alves, localizado no município de Juarez Távora, possui além da produção, uma área de beneficiamento/descaroçamento, que beneficia não apenas o algodão plantado no seu interior como nas demais localidades. Em trabalho de campo foi constatado que neste assentamento estão presentes 36 (trinta e seis) famílias, das quais 17 (dezessete) trabalham com o algodão colorido. Em média, cada agricultor consegue $1.500 \mathrm{~kg}$ por hectare. 
Em lugares onde o plantio se dá em área de plantio individual, uma das dificuldades encontradas, citada pelos agricultores, é a da colheita. Em algumas famílias, o número de integrantes é menor do que o necessário para esse processo, o que acaba dificultando e atrasando o trabalho. Dados obtidos através de aplicação de questionários no assentamento Margarida Maria Alves, no município de Juarez Távora, mostram que um dos principais problemas enfrentados pelos agricultores é a mão de obra. É o que demonstra o gráfico 1.

\section{Gráfico 1}

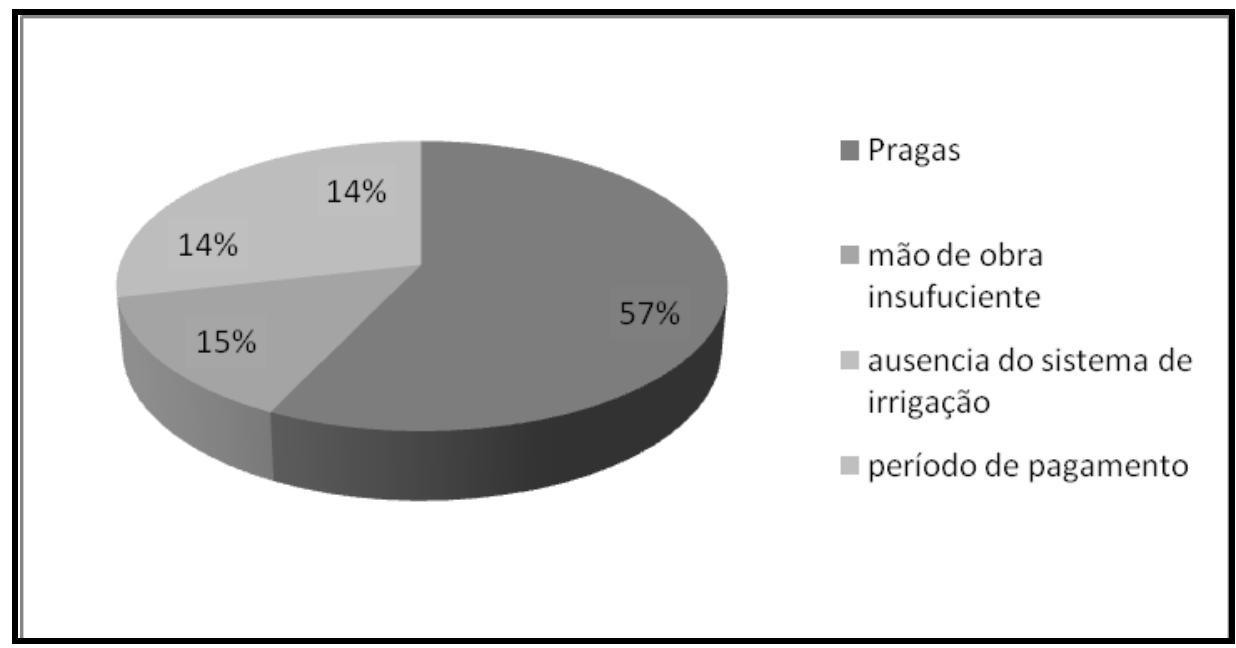

Fonte: Trabalho de campo, março de 2010.

Com base no gráfico 1 , pode-se observar que $57 \%$ dos entrevistados ${ }^{7}$ alega ser a praga o motivo das dificuldades com esse tipo de plantio. As demais respostas apontam a falta de mão de obra, a dependência de chuva para irrigar a plantação e o período de pagamento pelos compradores.

Beneficiado o algodão, a pluma chega a Campina Grande a fim de ser distribuída para as indústrias têxteis. Os cuidados em fiar a fibra de algodão colorido orgânico tornam difícil a parceria de indústrias têxteis dispostas a trabalhar com esse tipo de algodão. Devido a essa restrição, a pluma beneficiada segue para outras cidades, como a capital da Paraíba, João Pessoa e o vizinho estado de Pernambuco. 
Após esse processo, os tecidos retornam a Campina Grande onde se dá a fabricação e a comercialização das mercadorias. Todo esse percurso acaba encarecendo o produto final, o que gera um mercado consumidor formado por apenas algumas camadas sociais.

O algodão colorido orgânico é comprado das unidades produtoras com base no preço do algodão branco (commodity). Sobre o valor do algodão branco é acrescentado um percentual de $30 \%$ ou mais. A negociação de preços é realizada entre a cooperativa e os agricultores, baseada nos custos da produção do algodão colorido (FARIAS E RAMOS 2009). Durante a pesquisa, pudemos observar uma dessas reuniões da Rede Paraíba de Algodão Agroecológico, ocorrida em 2009. Nessa ocasião foram discutidos, dentre outros, o preço do algodão orgânico por tonalidade, ficando a pluma do branco a $\mathrm{R} \$ 5,00$, a do marrom, a $\mathrm{R} \$ 6,00$ e a do verde, a $\mathrm{R} \$ 7,50$.

\section{Produção dos derivados do algodão colorido e sua distribuição/comercialização}

Na cidade de Campina Grande, estão presentes várias cooperativas ligadas ao processo industrial do algodão colorido, destinadas à fabricação de roupas e artigos para decoração. São cooperativas que atuam no ramo há mais de 10 (dez) anos, formadas por indústrias têxteis, serigrafias, confecções e artesãos da cidade, a exemplo da Coopnatural.

A produção dos derivados do algodão colorido orgânico ocorre através da Cooperativa de Produção de Têxtil Afins do Algodão do Estado da Paraíba (Coopnatural), sediada em Campina Grande-PB. Esta é uma cooperativa articulada com a Rede Paraíba de Algodão Agroecológico. Participam da referida rede a Embrapa, agricultores familiares de 31 municípios, a Emater, o SEBRAE, ONGs, dentre outras empresas. As suas reuniões são momentos para discutir medidas que consolidem o avanço do algodão colorido na Paraíba.

A estrutura da cooperativa é composta pela Presidência, Setor Administrativo, Direção Administrativa Financeira, Diretoria de Produção, Conselho Fiscal e Conselho de Design. A consultoria mensal é realizada por um técnico de produção têxtil. A administração é realizada através de Assembléia Geral, Conselho de Administração e 
Conselho Fiscal, com atribuições estabelecidas em um Estatuto e um Regimento Interno.

A divisão do trabalho entre os cooperados é definida segundo a responsabilidade de cada cooperado: pela confecção de roupas, pela confecção de acessórios, pela serigrafia. Há uma subdivisão entre os cooperados para que todos participem do processo. As etapas de fiação, tecelagem e artesanato são terceirizadas, ficando a cargo de prestadores de serviços cuja relação é formalizada através de contratos.

A pesquisa identificou dez empresas cooperadas à Coopnatural na cidade de Campina Grande. Em seis delas foram realizadas visitas em que se fizeram entrevistas com o proprietário e levantamentos fotográficos. O mapa 2 mostra a espacialização das empresas na malha urbana da cidade. As empresas estão localizadas em sete bairros na sua maioria periféricos: Presidente Médici, Jardim Paulistano, Tambor, na Zona Sul e Bodocongó, na Zona Oeste. 
Mapa 2

Geo UERJ - Ano 13, nº. 22, v. 1, 1º semestre de 2011 - ISSN 1981-9021 http://www.e-publicacoes.uerj.br/index.php/geouerj 


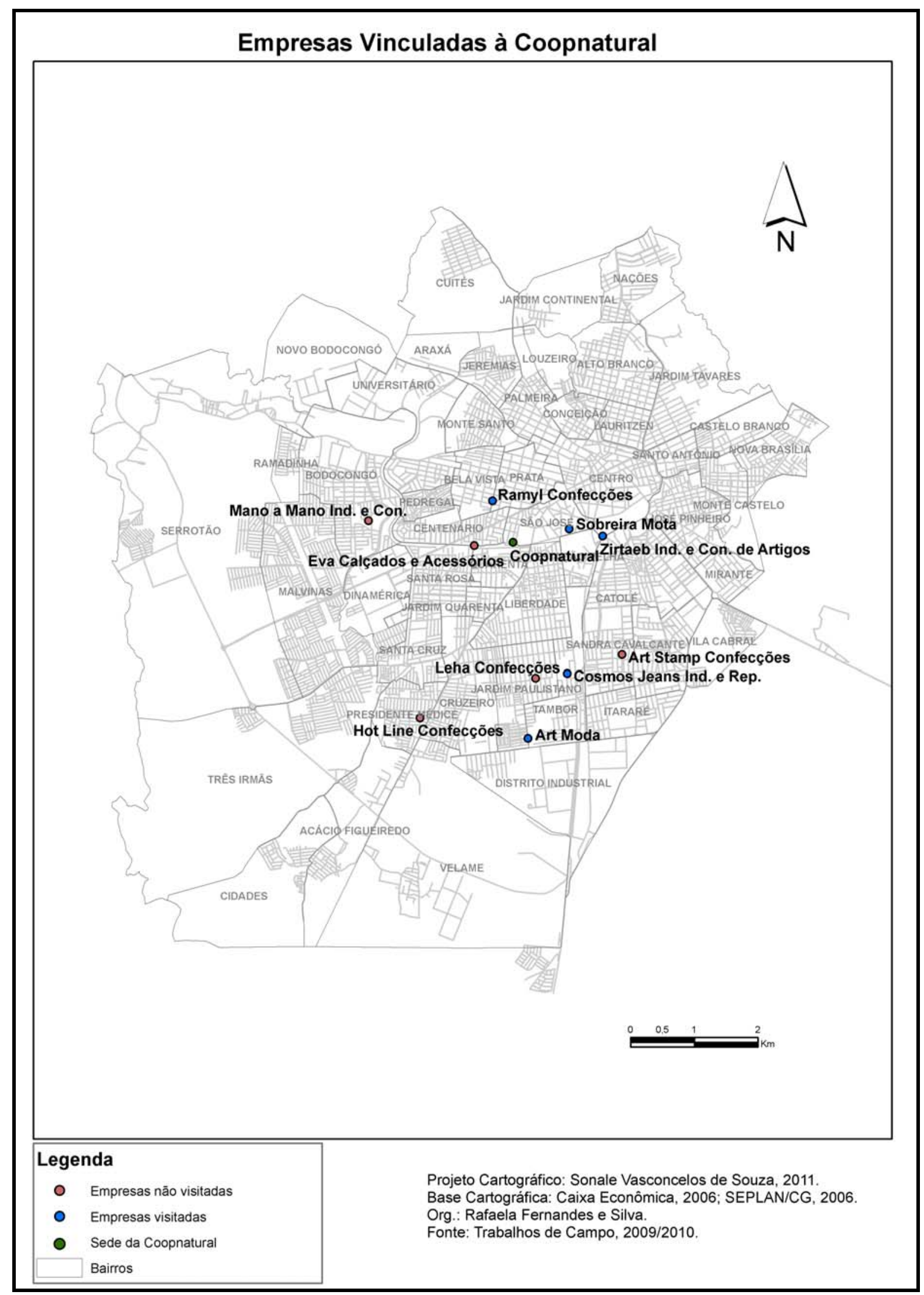

Geo UERJ - Ano 13, no. 22, v. 1, $1^{\circ}$ semestre de 2011 - ISSN 1981-9021 http://www.e-publicacoes.uerj.br/index.php/geouerj 
A elaboração dos tecidos do algodão colorido dá-se através da tecelagem manual, da tecelagem plana e da fabricação de malhas. O tecido manual, como vimos anteriormente, ocorre, através de teares manuais, na Entrefios, localizada na cidade de Campina Grande. A tecelagem plana é realizada na empresa têxtil Ribeiro Chaves, localizada em Aracaju-SE, onde são fabricados o brim (confecção de calças), o linhão (confecção de bermudas) e o tricoline (confecção de camisas). Para a fabricação da malha, a cooperativa tem parceria com a malharia Matesa, localizada na cidade de João Pessoa- PB. Aí são fabricados o Piquet canelado, o moletom, a meia malha e a ribana. Além dessas, a cooperativa ainda tem parceria com a Fiação e Tecelagem São José do Nordeste, localizada em Recife-PE e com a Unitextil, localizada na capital paraibana.

As empresas que realizam a fiação e a tecelagem para a Coopnatural são terceirizadas, aparecendo como prestadoras de serviço para as confecções.

Além da prestação de serviços da tecelagem, há ainda contratos com associações de bordadeiras, crocheteiras, labirinteiras, espalhadas pelo interior do Estado as quais enviam seus produtos para a sede da cooperativa, a fim de serem aplicados nas peças.

O tecido e/ou a malha prontos seguem para Campina Grande, para a sede da cooperativa, quando, então, se dá a etapa do corte, realizado em um só local, no caso a sede, para que não haja possíveis diferenças nas peças e para que se possa manter o padrão do tamanho, garantindo qualidade ao produto.

O designer, desenvolvido na própria sede da cooperativa, é criado seguindo as tendências da moda. Além do mais apresenta uma releitura da cultura nordestina vinculada às mais modernas tendências da moda internacional.

Via internet, o designer é enviado para a serigrafia responsável pelas estampas das peças. Então, a serigrafia cooperada recebe o designer e as peças. Uma das serigrafias é a Art Stamp Serigrafia, localizada na periferia da cidade de Campina Grande, administrada por duas pessoas com grau de parentesco e mais quatro funcionários contratados.

A pesquisa localizou as empresas de confecção que funcionam não apenas em estabelecimentos residenciais, bem como em estabelecimentos destinados a este fim. 
Trata-se de micro e pequenas empresas, algumas empregando mão de obra, outras funcionando com mão de obra familiar.

Os cooperados, então, representam pequenas empresas atuantes na cidade de Campina Grande que, visando entrar no mercado com um "novo produto", uniram-se em cooperativas para conseguir competir dentro dessa nova economia, com as empresas que atuam no cenário com tecnologia avançada.

O emprego familiar em pequenas empresas caracteriza o que Santos (2008b, p. 202) denomina circuito inferior da economia, circuito este que "absorve citadinos desprovidos de recursos e de qualificação profissional” e para o qual o trabalho é o fator mais importante.

Constata-se, assim, que a atividade individual ou familiar tem como objetivo o sustento da própria família, o que é uma característica da economia popular urbana nos termos definidos por Coraggio (1993, p. 19). Uma das características dessa economia popular, “se analisada dentro do modo capitalista de produção, é a baixa produtividade e o fato de reproduzir capital humano”.

Após o preparo final do produto, este retorna para a Cooperativa para a comercialização. As peças são armazenadas e passam pelo controle de qualidade por amostragem. As aprovadas recebem a marca Natural Fashion, anexada em sua etiqueta.

Na sede da Coopnatural, então, essas peças são embaladas sendo os produtos vendidos para lojistas cadastrados, localizados na maior parte do território nacional ${ }^{8}$ e em alguns pontos internacionais.

O consumo de mercadorias produzidas com o algodão colorido vem-se expandindo nos últimos anos, influenciando o aparecimento de diversas atividades econômicas ligadas a este produto, na cidade de Campina Grande. São as cooperativas formadas por confecções, serigrafias, artesãos e os estabelecimentos comerciais. Estes, por sua vez, extrapolam os limites regionais, estando espalhados não apenas no território brasileiro, mas também em vários países.

Segundo um dos funcionários da Coopnatural, a cooperativa quer atingir um público consumidor que tenha consciência em relação ao produto orgânico. Seus 
compradores são comerciantes que trabalham com o conceito de produto natural ou valores de preservação ambiental. Um dos pontos de venda no território brasileiro, que trabalha com tal “conceito” 9 , é o Mercado de Orgânicos, localizados em Curitiba-PR. Criado em fevereiro de 2009, o estabelecimento é o primeiro do gênero no país.

A comercialização é realizada apenas entre a cooperativa e os lojistas cadastrados, com exceção da loja estabelecida na sede da cooperativa, com o apoio do SEBRAE e que vende peças de produções passadas.

Assim como a concorrência sofreu uma mudança, o mesmo aconteceu com o consumo. Hoje em dia, através da publicidade, o consumidor já é preparado para o mercado do novo produto. Isso leva ao que Santos (2006b. p. 24) denomina de despotismo do consumo, "quando afirma que a chamada autonomia da produção cede lugar ao despotismo do consumo”. Daí o império da informação e da publicidade.

Como o consumo tem sua materialização no momento da compra, o comércio aparece como o cenário do consumo real. A mobilização da moda, em especial a moda ecológica, entra nesse cenário. No final da década de 90, “a visão integrada dos diferentes segmentos da indústria têxtil dá origem aos têxteis orgânicos” (SOUZA, 2000, p. 91).

Os consumidores finais dos derivados do algodão colorido orgânico encontramse distribuídos tanto no território nacional como em outros países. São 12 países que consomem o produto final produzido pela Coopnatural. O mapa 3 mostra os países que compram os derivados do algodão colorido orgânico, com destaque para Portugal, único país que possui uma franquia da cooperativa de exportação, isto é, único mercado que vende os derivados do algodão colorido importados da Coopnatural com direito de distribuição exclusiva. 
Mapa 3

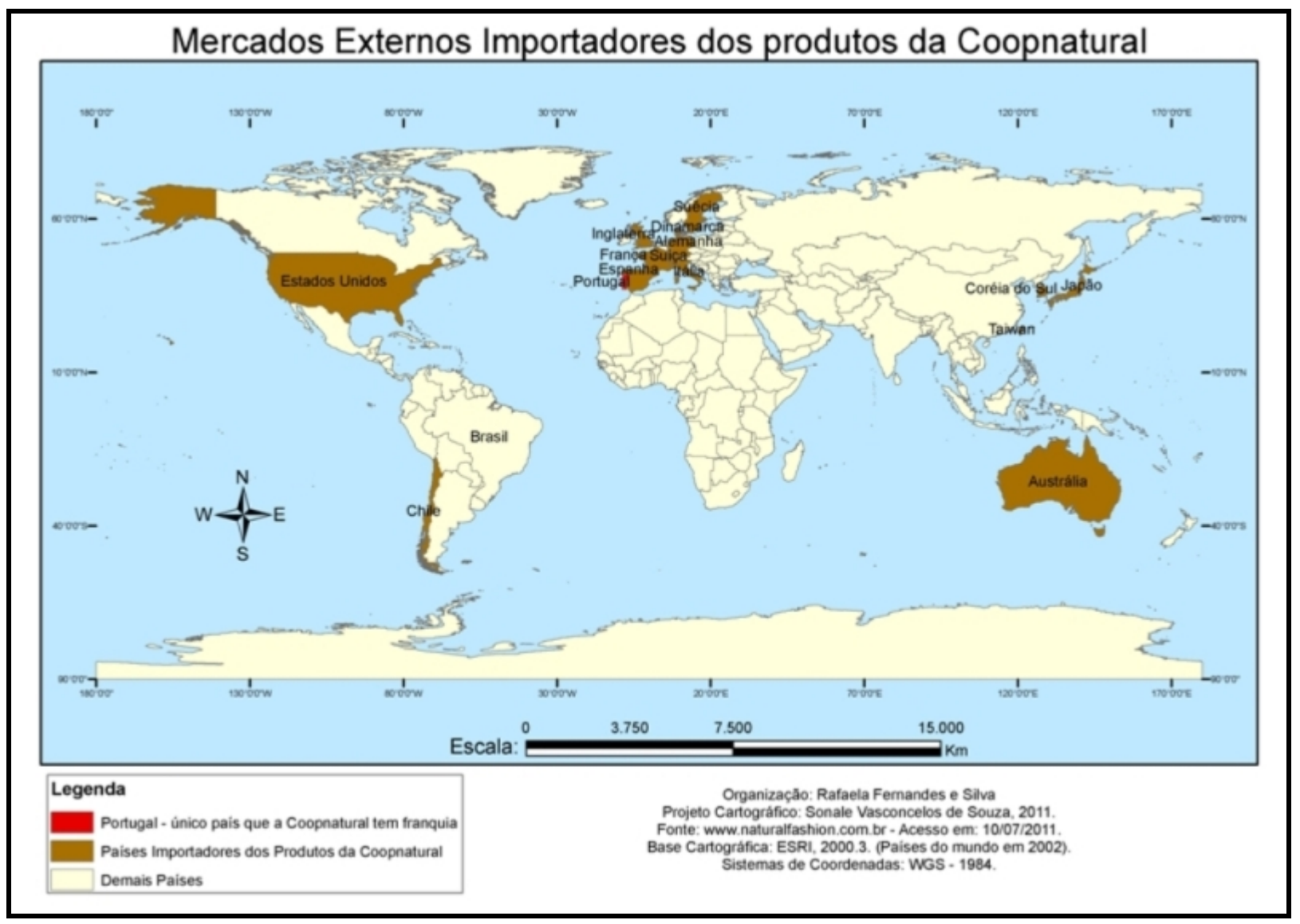

De acordo com o mapa 3, grande parte do mercado externo consumidor dos produtos da Coopnatural encontra-se na Europa, ficando alguns na América do Sul, a exemplo do Chile, na América do Norte, a exemplo dos Estados Unidos, na Oceania, a exemplo da Austrália, e na Ásia, a exemplo da Coréia do Sul, do Japão e de Taiwan.

\section{Considerações finais}

Geo UERJ - Ano 13, nº. 22, v. 1, $1^{\circ}$ semestre de 2011 - ISSN 1981-9021

http://www.e-publicacoes.uerj.br/index.php/geouerj 
Procuramos neste trabalho apresentar o circuito espacial do algodão colorido, em especial o orgânico, cultivado para atender as demandas da cooperativa Coopnatural, desde o cultivo do algodão tradicional à produção do algodão colorido.

O circuito espacial da produção do algodão colorido foi analisado segundo a concepção de Santos (1994). Durante a discussão, percebemos que esse circuito é resultado do avanço do meio técnico-científico-informacional, que se reflete nas novas dinâmicas espaciais de relação entre cidades e /ou regiões.

O algodão colorido, cuja semente é produzida pela Embrapa Algodão, tem como base o conhecimento científico, muito embora a sua origem remonte civilizações antigas. Porém com o aperfeiçoamento das técnicas e dos conhecimentos, foram introduzidas novas colorações e aperfeiçoamento para a produção das sementes. Tratase portanto de um produto que se insere na classificação da Agricultura Científica. A produção do algodão colorido dá-se principalmente em pequenas propriedades tendo por base o trabalho familiar. Trata-se portanto de uma nova configuração do processo produtivo que reúne novos conhecimentos e novas tecnologias associadas a práticas rudimentares, como as que se verifica nos campos de cultivo.

Percebemos também, a partir deste estudo, a transformação da relação cidadecampo, decorrente da inserção da tecnologia, da ciência e da informação desenvolvidas na cidade e levadas aos campos de produção, ou seja, a partir da troca de conhecimentos entre a empresa responsável pela criação da fibra do algodão colorido - Embrapa Algodão - e os agricultores que plantam essa fibra.

O circuito da produção do algodão colorido abrange uma diversidade de localidades, mas a pesquisa tomou por base a Coopnatural, cooperativa que agrega desde o fornecimento das sementes pela Embrapa Algodão, agricultores, a indústria têxtil, costureiras e bordadeiras, até chegar ao comércio internacional. Trata-se de um amplo processo produtivo, com escala internacional, mas que tem o local, mais especificamente a cidade de Campina Grande como loccus da distribuição e da gestão de todo o circuito. Verifica-se no processo analisado as transformações na relação campo - cidade, bem como a interrelação entre os circuitos inferior e superior da economia, em que o novo e o tradicional unem-se para suprir e impulsionar mercado consumidor. 


\begin{abstract}
Notas de rodapé
${ }^{1}$ Página eletrônica da Embrapa, http://www.cnpa.embrapa.br/acessado em 26/06/2011.

${ }^{2}$ Contaminação das lavouras do algodão pela praga do Bicudo, que levou a decadência dessa cultura na Região Nordeste.

${ }^{3}$ O CNPA (Centro Nacional de Pesquisa de Algodão) é dotado de vários campos experimentais: Patos, na Paraíba (com cultivos de algodão, gergelim e amendoim e pesquisas com fruticultura irrigada, com destaque para manga, caju, goiaba, banana, açafrão e uva); Barbalha e Missão Velha, no Ceará (onde são realizados estudos com gergelim, algodão, amendoim e mamona), Barreiras e Irecê, na Bahia; Primavera do Leste, no Mato Grosso (algodão) e Santa Helena, em Goiás.
\end{abstract}

\footnotetext{
${ }^{4}$ As cores existentes nativas de algodão colorido são a verde e as várias tonalidades do marrom. Caso haja necessidade de outras cores, será necessário optar por inovações biotecnológicas.

${ }^{5}$ Ver mapa 1.

${ }^{6}$ A comunidade serviu para a experiência do plantio da variação topázio. Nesse caso, a apanha foi realizada pela colheitadeira, para que não houvesse perigo de outros agricultores (exceto aqueles para os quais foram cedidas as sementes) terem acesso à colheita.

${ }^{7}$ Dentre os 17 que produzem algodão colorido no assentamento, apenas 7 responderam ao questionário.

${ }^{8}$ Com exceção dos estados do Acre, Rondônia, Roraima, Amazonas, Amapá, Ceará, Piauí, Sergipe e Espírito Santo.

${ }^{9}$ Termo utilizado pelo funcionário da Coopnatural em entrevista.
}

\title{
Referências
}

CORAGGIO, José Luis. La construcción de una economía popular como horizonte para ciudades sin rumbo. Itamontes, 1993.

ELIAS, Denise. Globalização e agricultura. São Paulo, Editora da Universidade de São Paulo, 2003.

FARIAS, Paulo Sérgio Cunha. Os circuitos espaciais de produção e os círculos de cooperação do algodão colorido e derivados da Paraíba (2000-2008): uma dimensão geográfica da flexibilização do produto, da produção e do consumo de moda, fibras, têxteis e confeç̧ões. Tese de Doutorado. Recife: 2010.

FARIAS, Adriana Salete Dantas. \& RAMOS, Francisco de Souza. Cooperação industrial: alternativa para a competitividade de micro e pequenas empresas. CESCAGE, 2009.

GRAZIANO DA SILVA, José. A nova dinâmica da agricultura brasileira. Unicamp, 1996.

LEFEBVRE, Henri. O direito à cidade. São Paulo: Centauro, 2001. 
MARAFON, Glaucio José. O trabalho de campo como um instrumento de trabalho para o investigador em geografia agrária. In: Geografia e pesquisa qualitativa: nas trilhas da investigação. PESSÔA, Vera Lúcia Salazar. RAMIRES, Julio Cesar de Lima Ramires. Uberlândia: Assis, 2009.

MONTE-MÓR, Roberto Luís. Cidade e Campo, Urbano e Rural. O Substantivo e o Adjetivo. In: O urbano e o regional no Brasil contemporâneo: mutações, tensões, desafios. Org. Sarah Feldman, Ana Fernandes. Salvador: EDUFBA, 2007.

MOREIRA, R. Pensar e ser em Geografia: ensaios de história, epistemologia e ontologia do espaço geográfico. São Paulo: Contexto, 2007.

SANTOS, Milton. Metamorfoses do espaço habitado. São Paulo: Editora: Hucitec, 1994.

USP, 2006a.

A Natureza do espaço. Técnica e tempo, razão e emoção. São Paulo:

Por uma outra globalização: do pensamento único à consciência universal. Rio de Janeiro: Record, 2006b.

Técnica, espaço, tempo: globalização e meio técnico-científicoinformacional. São Paulo: Editora da Universidade de São Paulo, 2008b.

SOUZA, Maria Célia de. Produção de algodão orgânico colorido: possibilidades e limitações. In: Informações econômicas. São Paulo, v. 30, 2000.

SOUZA, L. A. de. O território em rede na produção de algodão em Mato Grosso (MT). Anais do $2^{\circ}$ Simpósio O rural e O urbano no Brasil/UERJ. 2009. Rio de Janeiro, RJ. ISSN 1980 - 6396.

WHITACKER, Arthur Magon. Centralidade intraurbana e morfologia em cidades médias: transformações e permanências. XI Seminario Internacional RII - Red Iberoamericana de Investigadores sobre Globalización y Territorio. Mendoza, 2010.

Enviado para publicação em julho de 2011.

Aceito para publicação em agosto de 2011. 